\title{
RETRACTED ARTICLE: The Effect of Attention Cueing on Science Text Learning
}

\author{
Hui-Yu Yang ${ }^{1}$ Che-Chang Chang ${ }^{2}$
}

Published online: 10 September 2015

(C) Springer Science+Business Media Dordrecht 2015

This article has been retracted at the request of the corresponding author. The author identified errors in the data reported in his manuscript. Therefore the editor-in-chief of the journal and the Publisher decided that the most responsible course of action was to retract this paper. The corresponding author, Dr. Hui-Yu Yang, sincerely apologizes to the scientific community for any inconvenience that this might cause.

The online version of this article contains the full text of the retracted article as electronic supplementary material.

Electronic supplementary material The online version of this article (doi:10.1007/s10758-015-9264-6) contains supplementary material, which is available to authorized users.

Hui-Yu Yang

yangh936@163.com

Che-Chang Chang

2722524920@qq.com

1 Present Address: Foreign Language Department, Fujian University of Technology, Fuzhou, China

2 Business Management Department, Fujian University of Technology, Fuzhou, China 